\title{
Total Quality Environmental Management: Adoption Status in the Chinese Manufacturing Sector
}

\begin{abstract}
Purpose - To address the critical sustainability challenges currently faced by China, manufacturers in this country have committed to improve their environmental performance. To support this commitment, evidence suggests that Chinese manufacturers have mainly turned to the implementation of environmental management approaches such as ISO 14001, cleaner production, green supply chain management, circular economy and green lean. However, the adoption of other approaches such as Total Quality Environmental Management by Chinese manufacturers is less clear. This paper fills this gap by providing light into fundamental issues regarding the implementation of TQEM in the manufacturing sector of China.

Methodology/design/approach - A survey-based exploratory study was conducted based on 119 Chinese manufacturing companies and the data obtained was analysed using a combination of descriptive and inferential statistics.

Findings - The results revealed that in general, there is less awareness of TQEM in the Chinese manufacturing sector than other environmental and quality/operations improvement approaches such as green supply chain management, reverse logistics, ISO 9000, Six Sigma and lean six sigma. Thus, its degree of implementation is also lower than these approaches as well as ISO 14001. The results also indicate that although a company's size is not associated to the implementation of TQEM, it is mainly large organisations and those that have adopted TQM those which will be mainly aware and have implemented TQEM. The study also reveal the drivers, results and challenges of TQEM implementation.

Originality/value - The paper extends the currently limited knowledge on TQEM, and its results are beneficial for managers who aim at effectively adopting TQEM to simultaneously improve the environmental, operational and financial performance of their organisations. The paper can also motivate organisations not currently embarked on the "green wagon" to contemplate the benefits that implementing TQEM, or any other environmental management approach, may bring to their operations and business.
\end{abstract}

Keywords: China; Environmental Management Systems; EMS; Manufacturing; Total Quality Environmental Management; TQEM.

\section{Introduction}

China's manufacturing industry has not only become a main driving force of social development and economic growth for this nation (Zeng et al., 2010), accounting for 32.5\% of the GDP of this country (Wei and Balasubramanyam, 2015), but it has also transformed the world's economy. For example, nowadays China manufactures about $70 \%$ of the world's mobile phones, $80 \%$ of its air conditioners, and $60 \%$ of its shoes (The Economist, 2015), greatly contributing to the output of "Factory Asia", which now produces almost half of the world's goods. 
Despite its enormous economic contribution, the Chinese manufacturing industry is often criticized for being a major cause of environmental degradation, climate change, and natural resources scarcity (Zeng et al., 2008). China's current environmental challenges have been demonstrated by the fact that 16 of the 20 world's most polluted cities are located in China, rendering $8 \%$ to $12 \%$ of its annual GDP consumed to manage those issues (Economy, 2011). According to Wang et al. (2004), $40 \%$ of water pollution and $80 \%$ of air pollution in this country are generated by its manufacturing industry. In addition, Liu et al. (2016) found that products manufactured in China are associated with significantly higher $\mathrm{CO}_{2}$ emissions than the same goods produced elsewhere. These characteristics accentuate the environmental challenges currently faced by the Chinese manufacturing industry and the sustainable balance that it must achieve between serving as an engine of economic and social development while still preserving the environment.

In recent years, many Chinese manufacturing companies have committed to improve the environmental performance of their operations and actively respond to environmental regulations (Tseng et al., 2009). To support this commitment, the scholarly literature shows that Chinese manufacturers have adopted environmental management approaches and practices related to ISO 14001 (e.g. Zhang et al., 2014; Zhu et al., 2012), cleaner production (e.g. Chung et al., 2016; Geng et al., 2010), green supply chain management (e.g. Zhu et al., 2008; Zhu et al., 2005), circular economy (e.g. Zhu et al., 2010; Yuan et al., 2006), reverse logistics (e.g. Abdulrahman et al., 2014) and green lean (e.g. Zhan et al., 2016). However, the adoption of other also well-known environmental management approaches such as Total Quality Environmental Management (TQEM) is less clear. TQEM is a method which integrates Total Quality Management (TQM) principles and environmental strategies to eliminate waste and pollution to improve environmental performance (Curkovic et al., 2007). Empirical evidence suggests TQEM as an effective approach to improve the environmental performance of organisations by contributing to the elimination of waste and pollution as well as to achieve compliance with environmental regulations and quality strategies (Curkovic et al., 2008; Hanna et al., 2000). Additionally, the adoption of TQEM practices has also been associated to the achievement of cost savings by conserving and recycling energy as well as lowering future costs by mitigating environmental problems in advance (Curkovic et al., 2008).

Nevertheless, despite the relatively high degree of adoption of TQEM by Western manufacturing organisations (Harrington et al., 2008; Florida, 1996), there is very limited evidence of the level of implementation of this specific environmental management approach by Chinese manufacturers. Therefore, the main contribution of this paper lies in filling this research gap by providing evidence of the degree of adoption of TQEM in the Chinese manufacturing sector. In addition, TQEM seems to have received less attention in the academic literature, especially when compared to the relatively high volume of publications on other environmental management approaches such as green supply chain management, reverse logistics, ISO 14001, and lately green lean and circular economy. For this reason, this paper also contributes by expanding the limited body of knowledge on TQEM found in the academic literature when compared to that of other environmental management approaches. To achieve this, the paper addresses the following fundamental research questions:

What is the degree of awareness of TQEM among Chinese manufacturing organisations?

What is the degree of adoption of TQEM among Chinese manufacturing organisations?

What has stopped Chinese manufacturing organisations from more widely adopting TQEM? 
The rest of the paper is divided as follows: Section 2 discusses previous works conducted regarding the adoption of TQEM and highlights the limited volume of scholarly research carried out in this area; Section 3 presents the research methodology followed to address the formulated research questions; the results of the study are outlined and discussed in Section 4; whereas Section 5 presents the concluding remarks, limitations of the research and future research.

\section{Literature review}

Manufacturing organisations have been traditionally driven by prevailing objectives that include efficiency, profitability, customer satisfaction, responsiveness and quality (GarzaReyes, 2015). In particular, quality has been widely considered a determinant factor for the success and competitiveness of manufacturing companies (O'Neill et al., 2016; Garza-Reyes et al., 2015a). However, despite the importance of quality, and other operational objectives, environmental regulations and customer demands for greener products and services have forced manufacturing organisations to rethink these objectives by also considering the environmental impact of their operations. Thus, sustainable and green objectives are now well embedded as part of the corporate agenda of many manufacturing organisations, and these are hence required to be balanced with the traditional objectives. In this context, the academic literature suggests the existence of some synergy between some of the traditional organisational objectives, e.g. quality, and environmental sustainability. For instance, various authors such as Wiengarten and Pagell (2016), Narasimhan and Schoenherr (2012), Curkovic and Sroufe (2007) and Curkovic et al. (2000) have highlighted the importance of quality management systems and practices as facilitators of environmental management systems and as enablers to obtain higher returns from environmental management practices. The synergies between quality and environmental objectives, and the natural evolution of the quality and environmental management systems fields have contributed for these two fields to "intersect" and propose approaches which have evolved from previous evolutionary stages and both fields, see Figure 1. In this line, TQEM is an approach which has evolved from TQM and to support sustainability/environmental initiatives. Thus, TQEM intends to synergise the implementation and effects of quality management and environmental management systems to overcome common challenges when implemented separately, for example, conflicts for resource allocation and priority attention (Griffith, 2002).

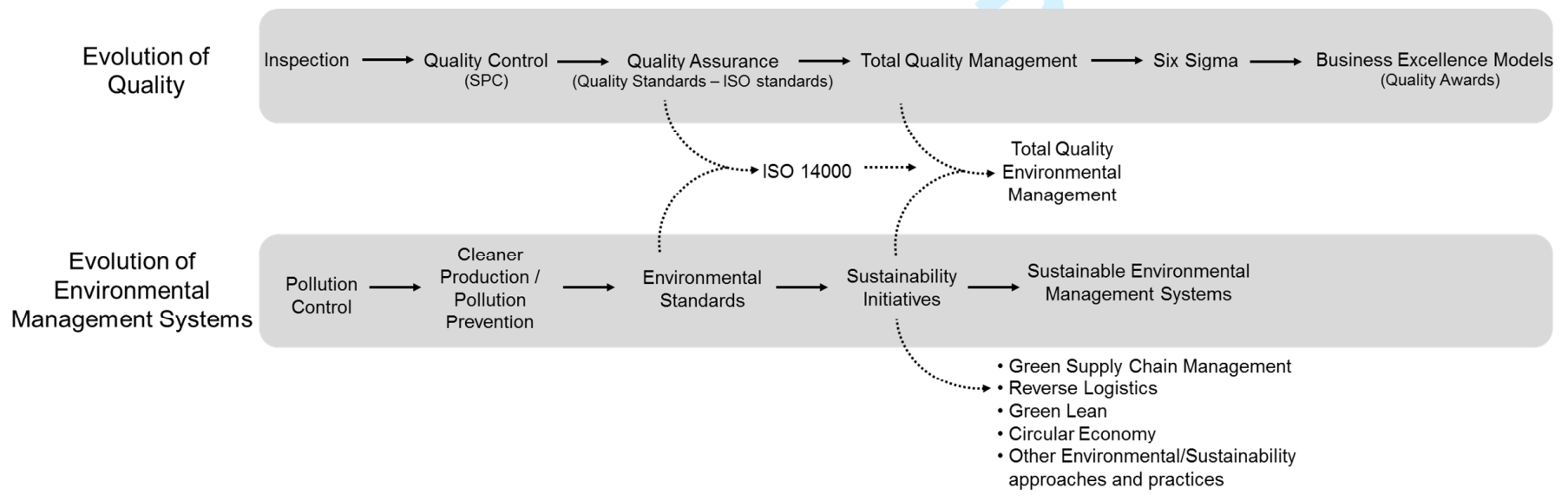

Figure 1. Evolution of the Quality and Environmental Management Systems fields (adapted from Beecroft, 2004 and Khalili and Duecker, 2013) 
TQEM was developed in 1992/1993 by the Global Environmental Management Initiative (GEMI), a group of then 21 companies formed in 1990, including IBM, AT\&T and Kodak, to foster environmental excellence in businesses (GEMI, 2017; Love et al., 2000). In this context, TQEM was born from the GEMI's intention of applying TQM principles and approaches to corporate environmental strategies. TQEM is therefore considered to have evolved from the traditional quality-focused TQM, see Figure 1, as it lacked concentration on environmental issues (Watson et al., 2000), which were gaining increasing attention since the mid1980s. Thus, TQEM focuses on integrating quality and environmental management principles to reduce and eliminate all waste steams within the design of products, their manufacture, utilisation and disposal (Sarkis et al., 2010). Although TQEM does not have a clear set of dimensions or standard definition (Zhu et al., 2012), Khadour (2010) comment that is centred on four fundamental principles, namely: (1) identification of external and internal customers; (2) continuous improvement; (3) doing the job right first time; and (4) taking a system approach.

A handful of exploratory studies have been conducted to investigate the acceptance of TQEM among industrialists. For example, a survey by Florida (1996) investigating the adoption of TQEM among S\&P manufacturing firms in 1995 found that $43 \%$ of these companies had adopted TQEM. Similarly, Harrington et al. (2008) conducted a study of 462 observations among 254 firms belonging to the S\&P500. The results of the study indicated that almost $67 \%$ (i.e. two-thirds) of the observations had adopted TQEM. Khadour (2010) explored the implementation of TQEM in the UK construction industry. The result of the study suggested that only $22 \%$ of 50 firms surveyed were not aware of TQEM, whereas the main driver for its implementation was found to be compliance to governmental environmental regulations. Khadour (2010) also found that the main benefits that construction companies obtained from the implementation of TQEM were cost savings and measurement of performance while the main barrier to its implementation was the lack of a clear implementation framework. Finally, Zhu et al. (2012) committed to exploring the influence of international pressures and domestic pressures on Chinese firms to be green. To do this, Zhu et al. (2012) considered ISO14001, TQEM and eco-auditing as examples of environmental management approaches. The result of the study indicated that international pressures have a positive impact on the adoption of TQEM and that its degree of impact is higher than that of domestic pressures. The results also revealed that $45.6 \%$ of the organisations surveyed had adopted TQEM, although a later study showed that only $22.9 \%$ of these companies had adopted TQEM successfully (Zhu et al., 2013). The studies from Zhu et al. (2012) and Zhu et al. (2013), however, have been limited to only explore the adoption of TQEM in China from a point of view of the adopting factors which influence such implementation.

Despite the above evidence, Curkovic et al. (2008) suggest that TQEM has not received the same level of acceptance in industry and academia as other approaches such as just-intime (JIT), TQM and time-based competition. This is also evidenced through the relatively low volume of research publications on TQEM when compared to that of other popular environmental management approaches. This limited volume of research calls for an opportunity to complement the studies of Florida (1996), Harrington et al. (2008), Khadour (2010), Zhu et al. (2012) and Zhu et al. (2013) and expand the very limited body of 
knowledge currently generated in the field of TQEM. This was the main motivational driver to conduct the research presented in this paper.

\section{Methodology}

\subsection{Survey questionnaire}

In order to address the research questions previously formulated regarding the adoption status of TQEM in the Chinese manufacturing sector, a survey questionnaire was considered as the most suitable method for the collection of primary data. In this case, an electronic version of the questionnaire was developed using Qualtrics. This facilitated the respondents' access to the questionnaire via mobile devices and web browsers as well as the easy transfer of the collected data to an Excel spreadsheet for an easy export to IBM SPSS Statistics software version 2015 for statistical analysis (Binti Aminuddin et al., 2016). The questionnaire was adapted from those of Garza-Reyes et al. (2012) and Antony and Desai (2009). In this line, due to the similarities of the present research with those conducted by Garza-Reyes et al. (2012) and Antony and Desai (2009), which respectively aimed at investigating the implementation status of lean manufacturing and Six Sigma in India, the questions formulated for their instruments were used as a basis to convey the questions of the instrument employed by this research. Thus, the questionnaire instrument designed for this research consisted of thirteen questions divided into three sections that intended to collect information regarding the demographics of the participants and their companies, their awareness of TQEM and implementation of TQEM in their organisations. Figure 2 presents an overview of the research's structure and questionnaire's logic and questions.

\subsection{Questionnaire validity and reliability}

Lancaster (2008) indicates that in order to obtain validity and reliability in a survey instrument it is important to inspect the variables or data from the literature review that constitute the survey in the form of questions before the instrument is distributed. To achieve a valid and reliable instrument, reliability threats such as subject or participant error, subject or participant bias, observer error and observer bias were confronted by conducting a small pilot study as suggested by Robson and McCartan (2016).

For this purpose, the questionnaire was distributed to ten credible participants that included five manufacturing managers from China and five academic experts in the field. This resulted in the questionnaire instrument being amended and improved to eliminate participants' errors and bias. In particular, the academic experts' feedback was considered to ensure that the questions in the instrument addressed the fundamental research questions and to improve the clarity and comprehensiveness of some of the questions included. Thus, ambiguities when understanding and answering questions and irrelevant questions were eliminated based on the academic experts' feedback. The manufacturing managers' advice was followed by adding extra profile questions such as industrial experience of the participants and size of the company in order to test some correlations among the occurred results.

Since the questionnaire instrument used fixed-alternative questions, these did not require interpretation. Therefore, the last two threats (i.e. observer error and observer bias) were not relevant in this case (Binti Aminuddin et al., 2016). 


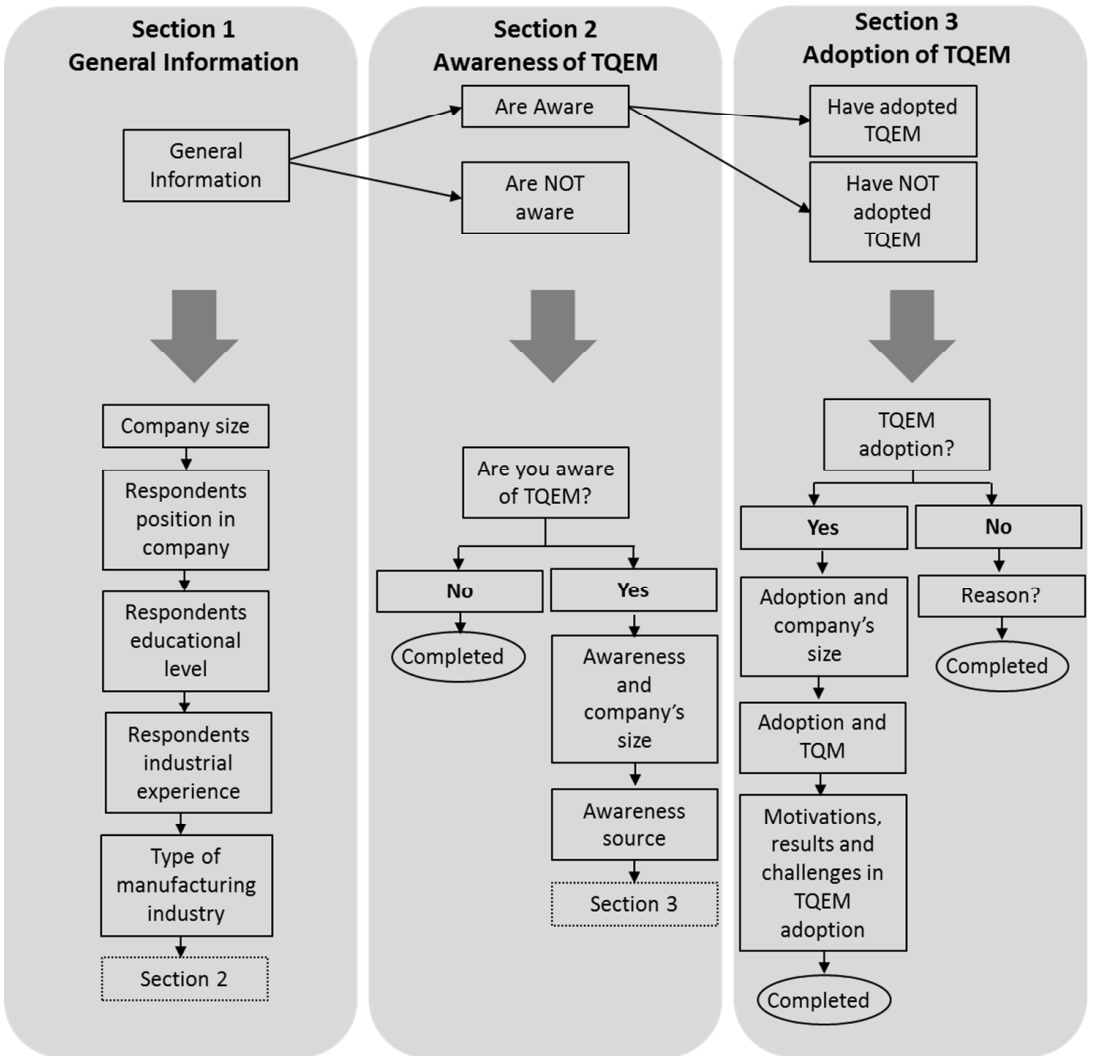

Figure 2. Research's structure and questionnaire's logic and questions

\subsection{Questionnaire distribution}

The questionnaire was distributed via e-mail among 150 Chinese manufacturing companies located in various provinces of China. The participant organisations were randomly identified and selected from directories and data bases that included Global Sources, LinkedIn, Amadeus and IQS Directory, whereas some others were personal contacts of the authors. The target respondents included top managers, middle level managers, engineers, front-line managers, etc. from various departments such as production, maintenance, environmental, maintenance, design, purchasing, etc. This contributed in providing information about TQEM from different organisational perspectives. Additionally, this type of respondents, and their backgrounds, were considered to have a deeper and more accurate understanding of the company's operations and performance before and after the implementation of TQEM.

Out of the 150 questionnaires distributed, a final total of 119 valid responses were obtained, resulting in a response rate of $79.3 \%$. Based on comparative sample sizes used in similar survey-based studies related to environmental management approaches (e.g. Teixeira 
et al, 2016; Khor et al., 2016; Khadour, 2010; Vachon, 2007) the sample size of 119 responses used in this study was considered acceptable to conduct an exploratory analysis and draw initial conclusions regarding the implementation status of TQEM in the Chinese manufacturing sector.

\section{Results and discussion}

\subsection{Organisations and participants' profiles}

Figure 3 presents an overview of the profile of the organisations and subjects from the Chinese manufacturing industry that participated in the survey. In terms of the organisation's size, see Figure 3(a), the standard Chinese classification was used to categorise the respondents' organisations, i.e. large $>1,000$ employees, medium between 300-1000 employees, small between 20-299 employees and micro<20 employees (China Briefing, 2011). Most of the responses came from employees in tactical, i.e. middle level, see Figure 3(b). Middle level employees represent one of the most valid sources of information, and they normally participate in and lead the adoption and management of new working methods and practices in their organisations (Carter et al., 1998). This characteristic, and the fact that $80 \%$ of the respondents had university education, see Figure 3(c), and significant years of working experience, see Figure 3(d), can be considered factors which support the credibility of this study (Kirkham et al., 2014). Finally, the study was not limited to a specific manufacturing industry but it considered the entire manufacturing spectrum, see Figure 3(e). In this case, "others" represented industries such as energy production, steel processing, metallurgical, clothing and fast moving products.

\subsection{TQEM awareness}

The study indicated that $61 \%(n=73)$ of the participant organisations were aware of TQEM while $39 \%(n=46)$ were not. This suggests that TQEM may be less known in the Chinese manufacturing sector when compared to the UK's construction sector (Khadour, 2010). Due to the limited research of TQEM in the scholarly literature it is difficult to establish a comparative base between the awareness of TQEM in the Chinese manufacturing sector and other industrial sectors and countries. However, when compared to the awareness of other environmental management approaches, TQEM seems to have gained less acceptance over the years. For example, Zhu et al. (2005) suggest that the level of awareness of green supply chain management in China is high. Lau and Wang (2009) also indicate that the awareness of reverse logistics in the Chinese electronic industry has increased. Similarly, Xue et al. (2010) found that most Chinese officials working at municipal and county levels have high awareness and understanding of the circular economy concept. The level of awareness of TQEM among Chinese manufacturers found in this study may not be considered low. However, taking into consideration that TQEM is a relatively mature approach that was first discussed in the academic literature by the beginning of the 1990s and that green supply chain management, reverse logistics and circular economy are more contemporary environmental management approaches, it may be concluded that TQEM has not gained the same level of acceptance in China as these approaches. Considering that the TQEM's predecessor (i.e. TQM) has been widely implemented in China and it has provided the expected results (Yusuf et al., 2007), a higher awareness of TQEM in China would have probably been expected. 


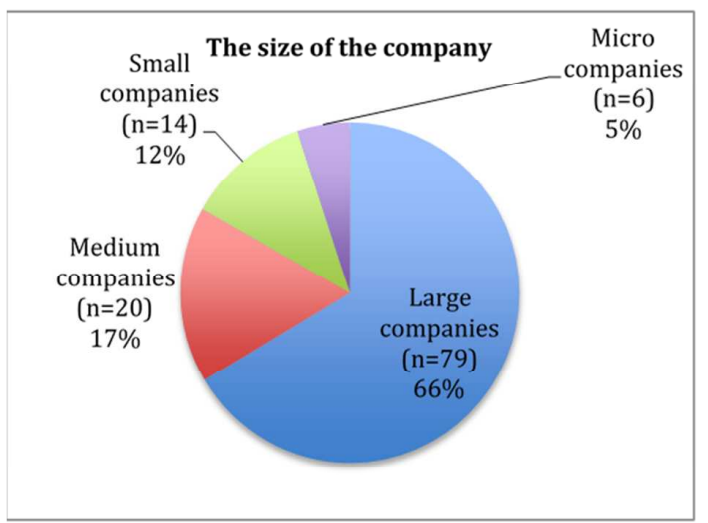

(a)

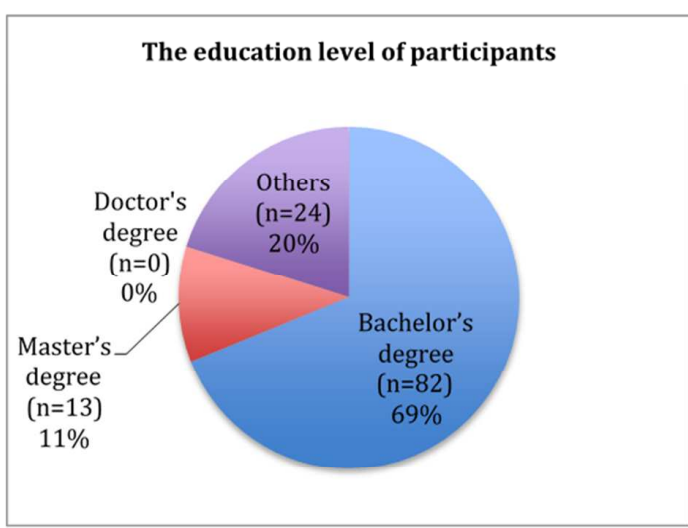

(c)

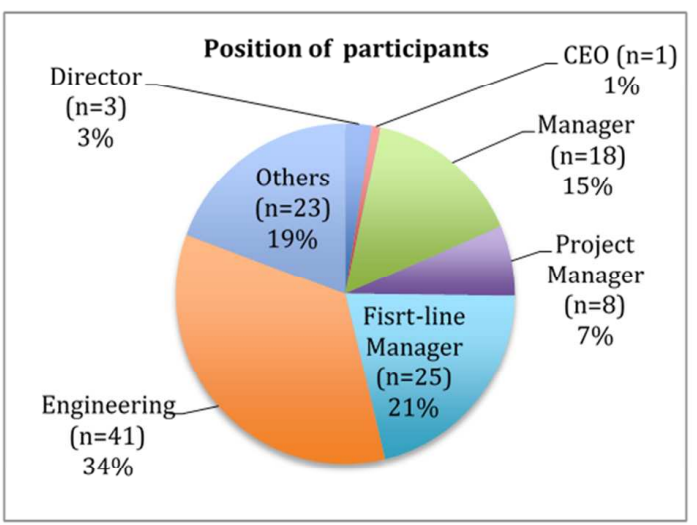

(b)

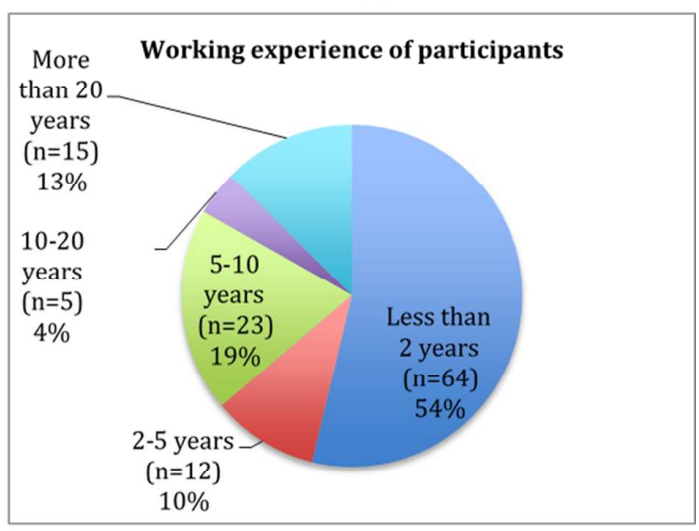

(d)

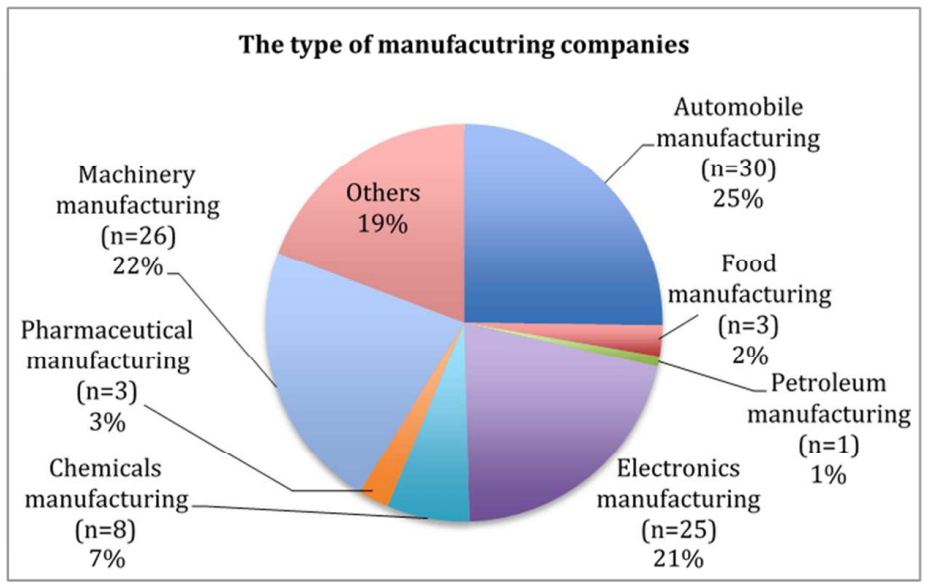

(e) 
Figure 3. Profile overview of respondents and their organisations in relation to (a) size of the company, (b) position, (c) educational level and (d) working experience of the participants, (e) manufacturing industry

When comparing the awareness of TQEM to other quality and operations improvement approaches, its growth also seems to be more limited. For instance, Vouzas and Psychogios (2007) commented that the degree of awareness of ISO 9000 among Northern Irish executives was high, with almost nine out of ten executives (88\%) having heard about it. Antony and Desai (2009) found that out of 290 Indian organisations from various industrial sectors $264(92 \%)$ of them were aware of Six Sigma. Lee et al. (2013) found that out of 50 UK organisations from various industries $33(66 \%)$ of them were aware of lean six sigma. It is difficult to explain the reasons as to why TQEM has not gained a wider level of acceptance in both industrial and academic circles not only in China but also around the world. However, the abundance of TQM failures published in the academic literature (Soltani et al., 2005) may have contributed to hinder the acceptance and popularity of TQEM.

\subsubsection{TQEM awareness and company's size}

From the 73 organisation that were aware of TQEM, 50 were large $(50 / 79=63 \%), 14$ medium $(14 / 20=70 \%), 6$ small $(6 / 14=43 \%)$ and 3 micro $(3 / 6=50 \%)$. It is common to find a wider implementation trend of best practices such as TQM, JIT, ISO 9000, ISO 14000, kaizen and six sigma in larger manufacturing organisations (McLaughlin, 2013). Thus, finding out that $87 \%$ of the Chinese manufacturing companies that were aware of TQEM had more than 300 employees can be considered an expected phenomenon.

\subsubsection{Source of awareness}

In terms of the source of awareness, $62 \%$ of the respondents came to know about TQEM from personal education, $32 \%$ from top management, $26 \%$ from professional publications and $16 \%$ from consultancy agencies. Other sources of awareness included customers, business partners and company quality/environmental programmes. In this case, respondents were given the opportunity of selecting more than one source. Determining that personal education is the main source of awareness of TQEM in the Chinese manufacturing sector is unsurprising, considering the fact that almost 500,000 Chinese students carry out their studies abroad (ICEF Monitor, 2015), especially in Western countries where approaches such as lean manufacturing, six sigma, supply chain management, total quality management, among others, are well embedded within a large range of engineering and business management programmes. Top managers and professional publications serving as important sources of awareness on TQEM is in line with the studies of Garza-Reyes et al. (2012) and Antony and Desai (2009), which also found these as relevant sources of awareness on lean manufacturing and six sigma in India.

\subsection{TQEM adoption}

The results of the study showed that out of the 119 organisations that participated in the research, $43 \%(n=51)$ had adopted TQEM while the rest $57 \%(n=68)$ had not. This is in line with the study of Zhu et al. (2012), which found that out of 377 companies investigated $45.6 \%$ of them had adopted TQEM. The relatively low implementation of TQEM in the 
Chinese manufacturing industry corroborates the previous finding regarding its also limited awareness in China despite it may be considered a mature environmental management approach and China has faced critical environmental burdens since few decades ago (Zhu et al., 2013). Zhu et al. (2012) suggest that TQEM fits well within the Chinese context in terms of supporting various general regulatory policies, such as those established by the Circular Economy. However, this has not reflected in its wider adoption.

In relation to other environmental management approaches, although TQEM is considered a variation of ISO 14001, and vice-versa (Curkovic et al., 2005), the adoption of ISO 14001 seems to have found much more proliferation in China than TQEM. For example, Qi et al. (2011) comment that over 35,000 organisations in China had already implemented ISO 14001 by the end of 2009. The difference in their degree of implementation may come from the fact that ISO 14001 is an increasingly common requirement for accessing markets (Stalley, 2009) while TQEM is not. Similarly, green supply chain management, circular economy and reverse logistics all seem not only to enjoy a wider recognition and awareness than TQEM, see Section 4.2, but also a more prominent role as the emphasis paid on these environmental management approaches in the scholarly literature, within the context of China, suggests their wider implementation (e.g. Chung et al., 2016; Geng et al., 2010; Zhu et al., 2008; Zhu et al., 2005; Zhu et al., 2010; Abdulrahman et al., 2014). Since no other reported application, or study, of green lean exists in the academic literature within the context of China, besides that presented by Zhan et al. (2016), it may be assumed that TQEM has been more widely deployed than this more contemporary approach.

When compared to other quality and operations improvement approaches, Taj (2008) found that lean manufacturing is not very common in Chinese factories while Lee et al. (2011) commented that only very few companies in this country are involved in the implementation of six sigma. In the case of TQM, Yusuf et al. (2007) found that its implementation in China has been extensive. Although it would be too adventurous to conclude that TQEM has been more widely implemented than lean manufacturing and six sigma in the Chinese manufacturing sector, this evidence may suggest that this could be the case. However, a specifically designed comparative study may need to be conducted to gain a more reliable and accurate insight into this. In any way, based on the huge popularity and amount of literature and empirical studies found in the body of knowledge of lean and six sigma, it will not be difficult to assume and accept that quality and operations improvement approaches like these two have been more widely implemented worldwide than TQEM. Again, further research will need to be conducted to scientifically confirm this assumption.

\subsubsection{Company's size and implementation of TQEM}

It is commonly hypothesised in the scholarly literature that large organisations have more positive attitudes towards the implementation of quality and operations improvement approaches than small companies (McLaughlin, 2013; Taj, 2008). To explore this phenomenon within the context of TQEM, a correlation analysis was performed, the results are presented in Table 1.

Table 1. Correlation analysis - Size of the company and degree of TQEM adoption

\begin{tabular}{|l|c|c|}
\hline & \multicolumn{2}{|c|}{ TQEM adoption } \\
\hline The size of companies & Yes $=1$ & $\mathrm{No}=0$ \\
\hline Large companies=1 & $38(1,1)$ & $41(1,0)$ \\
\hline Medium and SMEs $=0$ & $13(0,1)$ & $27(0,0)$ \\
\hline
\end{tabular}


Size of the company and degree of TQEM adoption

Hypothesis 1: the degree of TQEM adoption is positively associated with the size of the company.

\begin{tabular}{|l|l|l} 
Correlation Coefficients & 0.14308 & $<0.3$
\end{tabular}

Since the correlation analysis showed a coefficient $<0.50$, i.e. 0.14308 , then the results indicated that the degree of adoption of TQEM is not associated to a company's size. The lack of similar analyses on TQEM makes its comparison with previous results impossible. However, if compared to other quality and operations improvement approaches, e.g. adoption of lean or quality practices, these results support the findings of Garza-Reyes et al. (2015b) in relation to the adoption of lean in the Turkish automotive suppliers industry and those of Mallur et al. (2012) and Al-Najem et al. (2013) in relation to the adoption of quality practices. In these cases, these studies found that the size of a company does not affect the implementation of these quality and operations improvement approaches. The results, however, contradict the studies of Sezen et al. (2012) and Bakas et al. (2011), which found that a company's size has an effect on the implementation of lean, with small organisations struggling more with such activity. These contradictory results call for further research to determine whether the size of a company has any inference of the implementation of TQEM.

\subsubsection{TQM and implementation of TQEM}

Although TQEM is committed to using TQM approaches (Harrington et al., 2008), and King et al. (2005) suggest that companies that have implemented TQM are more likely to adopt TQEM, no empirical evidence has been provided to explore such relationship. Therefore, a correlation analyses was performed, see Table 2 .

Table 2. Correlation analysis - Relationship between TQM and TQEM adoption

\begin{tabular}{|c|c|c|}
\hline & \multicolumn{2}{|c|}{ TQEM adoption $(\mathrm{Y})$} \\
\hline TQM adoption & Yes $=1$ & No $=0$ \\
\hline Yes $=1$ & $49(1,1)$ & $29(1,0)$ \\
\hline $\mathrm{No}=0$ & $2(0,1)$ & $39(0,0)$ \\
\hline
\end{tabular}

\begin{tabular}{l}
\hline \multicolumn{3}{c}{ Relationship between TQM and TQEM adoption } \\
\hline Hypothesis 2: The degree of TQEM adoption is positively associated with the degree of \\
TQM adoption. \\
\hline Correlation Coefficients \\
\hline
\end{tabular}

The correlation results indicated a correlation coefficient $>0.50$, i.e. 55368, which suggested that the adoption of TQEM was positively associated to the implementation of TQM, a regression analysis to further explore this relationship was conducted as suggested by Hayter (2012), see Table 3.

Table 3. Regression analysis - Relationship between TQM and TQEM adoption

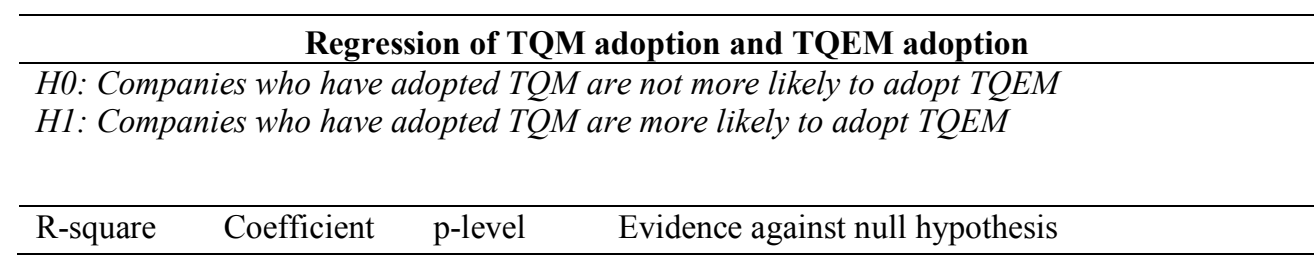




\begin{tabular}{llll}
\hline 0.30959 & 0.53431 & $5.02718 \mathrm{E}-11$ & very strong
\end{tabular}

The regression analysis indicated that $53 \%$ of the companies that have adopted TQM will also adopt TQEM. Since the p-value is $<0.001$ the evidence against the null hypothesis $(H O)$ is strong (Hayter, 2012), thus it was rejected. Therefore, it can be concluded that companies which have adopted TQM are more likely to also adopt TQEM. This suggests that although TQM has been more widely implemented than TQEM, e.g. out of the 119 companies that participated in the study $66 \%(\mathrm{n}=78)$ had implemented TQM and only $35 \%(\mathrm{n}=41)$ had adopted TQEM, the implementation of the second may also increase in the future due to the wide acceptance of TQM in China (Yusuf et al., 2007).

\subsubsection{Drivers, results and challenges of TQEM implementation}

Figure 4 presents the (a) main drivers which motivated the Chine manufacturing companies that participated in the study to implement TQEM, (b) the results they obtained from such implementation, and (c) the main challenges they faced during the TQEM's deployment. Participants were given the opportunity of selecting as many answers, i.e. drivers, results and challenges, they considered played a role during and after the implementation of TQEM. This "multi-selection strategy" allowed the study to obtain a more accurate picture of the phenomenon under study (Azzara, 2010).

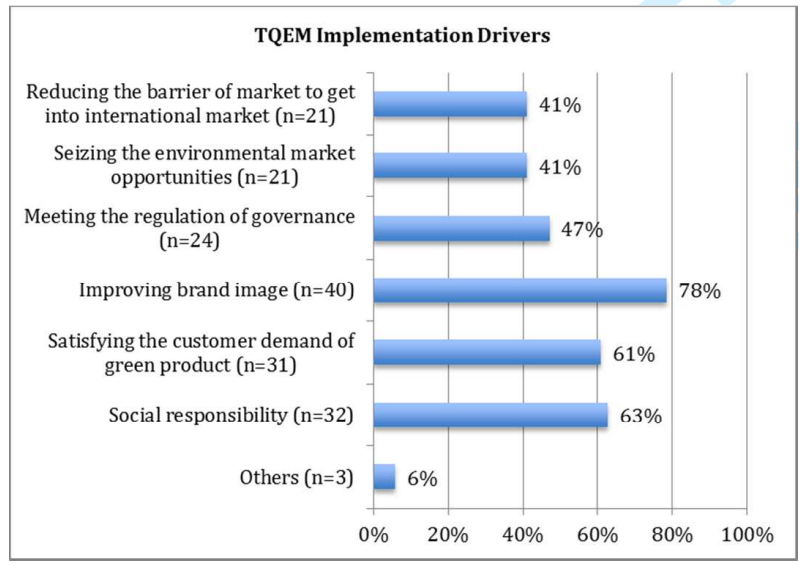

(a)

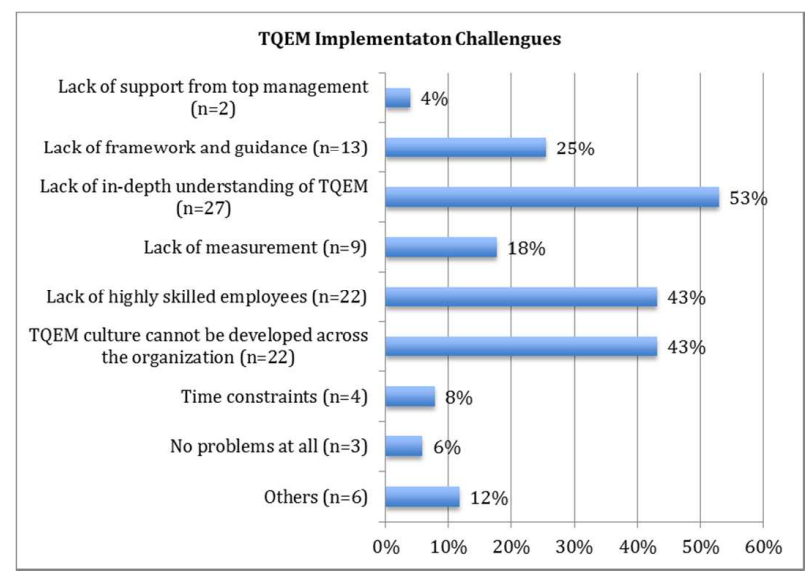

(c)

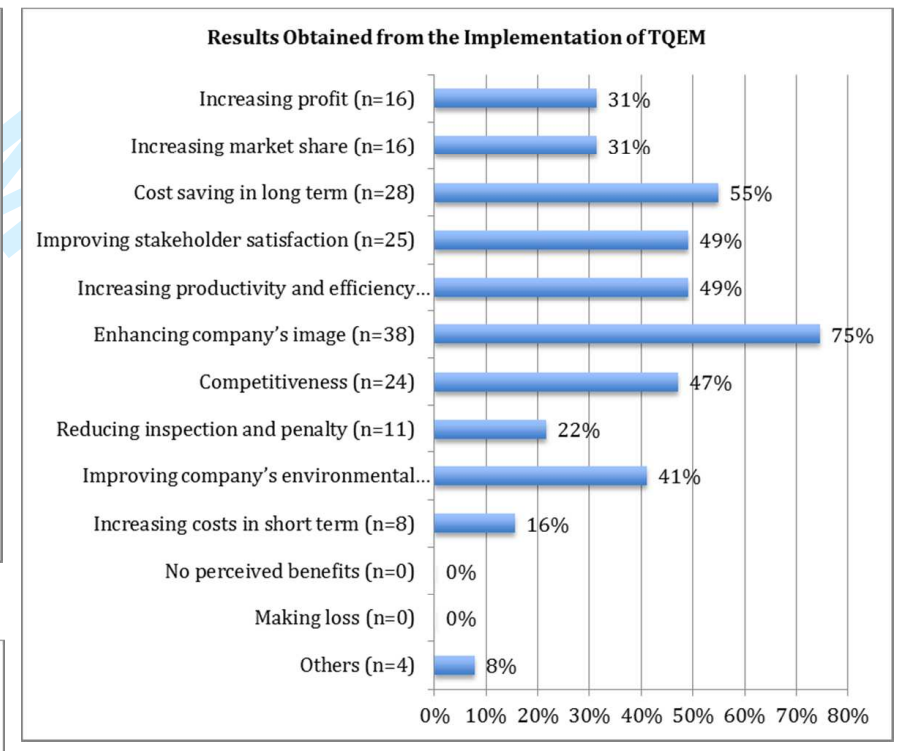

(b) 
Figure 4. (a) Drivers, (b) results and (c) challenges of TQEM implementation

Choosing to implement TQEM to improve brand image, see Figure 4(a), is a reasonable business driver for manufacturing companies in China as Zhu et al. (2010) showed that $67 \%$ of Chinese and $42 \%$ of US consumers prefer to buy products/services from companies that enjoy an environmental reputation. The results obtained from the implementation of TQEM indicate that Chinese manufacturers are actually benefiting from a better company's image, see Figure 4(b). In the case of the second most important driver (i.e. social responsibility), see Figure 4(a), since environmental problems have seriously affected people's daily life in China, it is not surprising to see that manufacturing companies want to contribute to address this issue through the implementation of TQEM. In relation to the cost savings achieved by the implementation of TQEM, see Figure 4(b), this is in line with the views of Khadour (2010), Curkovic et al. (2008) and Harrington et al. (2008), who comment that one of the objectives of TQEM is to improve internal operation efficiency and reduce costs while simultaneously achieving environmental excellence.

On the other hand, lack of in-depth understanding was found to be the main barrier faced by the companies when implementing TQEM, see Figure 4(c). This is a common barrier in the implementation of quality and operations improvement approaches as shown by GarzaReyes et al. (2012) and Antony and Desai (2009). A reason for this barrier may be the fact that, like lean (Pingyu and $\mathrm{Yu}, 2010$ ), TQEM has not yet gone beyond the environment of some research institutes, universities and international corporations. This is also in line with the second most important barrier related to the lack of highly skilled employees, which is normally a critical success factor to implement any improvement approach (Antony and Desai, 2009). Like TQM, TQEM is based on the participation of everyone within an organisation (Zhu et al., 2013; Curkovic et al., 2005). The results indicate, see Figure 4(c), that Chinese manufacturing companies are struggling to develop a TQEM culture that goes across the entire organisation. This is contradictory to the now well recognised need among Chinese companies for them to address the environmental challenges that the country is facing (Zhu et al., 2008; Zhu et al., 2005).

\subsection{Impeding factors in TQEM implementation}

Respondents from the 68 organisations that had not implemented TQEM were asked to identify the main impeding factor that they considered had stopped their organisations from adopting TQEM. The results are presented in Figure 5.

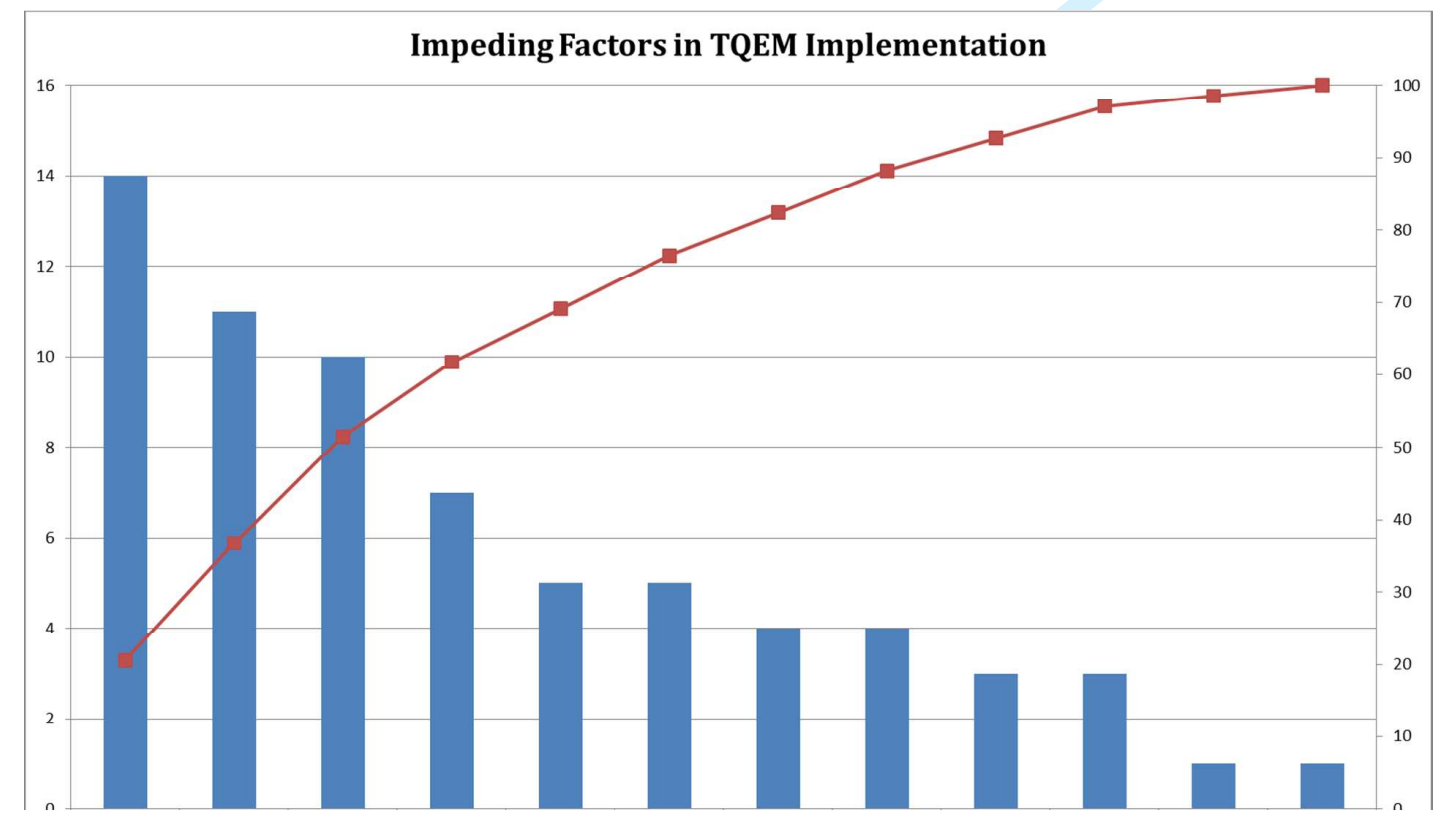


Figure 5. Main impeding factors to TQEM implementation

The results of the study corroborate, once more, the relatively low popularity and acceptance of TQEM in the Chinese manufacturing sector as the respondents suggested "lack of awareness" as the main impeding factors for not implementing TQEM. Possible reasons for this have been discussed in previous sections. In response to the critical environmental issues faced by the country, the Chinese government has stepped in by enacting acts on environmental protection and laws, and support state-owned medium-sized and large enterprises with technological overhaul for reducing sources of hazards and pollution (Zeng et al., 2010). Similarly, it has also strongly promoted the implementation of ISO 14001 (Zeng et al., 2005). A similar promotion of TQEM in the Chinese manufacturing sector may be convenient to support all the environmental strategies and actions already rolled out by the Chinese government. As suggested by Zhu et al. (2012) and Curkovic et al. (2005), TQEM can support policies and strategies, such as circular economy and ISO 14001, geared towards jointly improving economic and environmental performance (Yuan et al., 2006).

Despite the recognised consciousness of the Chinese government (Zhu et al., 2012; Zeng et al., 2010), manufacturing industry (Tseng et al., 2009) and society in general regarding the critical environmental challenges faced by China, this seems not to have filtered down appropriately to a company's level as "lack of support from top management" was found to be the second highest barrier, see Figure 5. Top management support has been widely recognised in the academic literature as a cornerstone factor for the successful implementation of any quality and operations improvement approach (Talib et al., 2011; Zu et al., 2008). Thus, if Chinese manufacturers are to successfully implement TQEM, or any other environmental management approach, support, commitment and leadership from companies' executives must be provided. To gain their commitment, the Chinese government can formulate appropriate strategies based on economic incentives or create laws to force them to actively participate in the implementation of green programmes such as TQEM. Additionally, the government can provide "awareness training" to executives, which would help in developing a sense of urgency and ownership regarding their role, and that of their companies, in improving the environmental conditions of China.

"Lack of expertise" and "lack of knowledge and training" were also found to be important impeding barriers to the implementation of TQEM. Expertise, knowledge and training are also considered critical success factors for the successful implementation of any quality and operations improvement approach (Talib et al., 2011). Developing learning and training within Chinese manufacturing companies will contribute in creating a well-trained workforce which will eventually play a critical role in successfully implementing any environmental management approach, including TQEM.

Alkhidir and Zailani (2009) and Min and Galle (2001) have identified high cost as one of the major challenges to the implementation of green supply chain practices. The results of the 
study show that this is also the case for the implementation of TQEM. Like any other green and quality and operations improvement approaches, the implementation of TQEM will require commitment and investment not only in terms of effort and time but also in terms of resources, including that of capital. This, and the fact that most environmental management approaches do not deliver immediate financial benefits (Nidumolu et al., 2009) make this a critical barrier to the implementation of TQEM. However, once effectively implemented, TQEM will not only help organisations in improving their environmental performance but also their financial performance through the reduction of operational costs and savings (Khadour, 2010; Curkovic et al., 2008; Harrington et al., 2008). This should serve as an incentive for the Chinese government to help organisations, especially small and medium size enterprises, to mitigate these initial costs through some form of government support.

Finally, although the respondents were given the opportunity of mentioning any other barrier, besides those provided to them as part of the fixed-alternative questions, none of them cited the lack of a clear implementation framework, such as in the case of the UK's construction sector (Khadour, 2010), as an impeding factor for the implementation of TQEM.

\section{Concluding remarks, limitations and future research directions}

Much of the dramatic growth of China over the last decade has been fuelled by a strong manufacturing base that has served the country, and indeed the world, as an engine of economic and social development. This growth, however, has been accompanied by equally dramatic environmental problems such as environmental degradation, climate change, and natural resources scarcity. To address these concerns, substantial academic research has been devoted to study the application of environmental management approaches such as ISO 14001, cleaner production, green supply chain management, circular economy, reverse logistics and green lean by Chinese manufacturing organisations. However, very limited research has been conducted regarding the application of TQEM. Therefore, this paper is among the very first studies which have investigated the degree of adoption of TQEM by Chinese manufacturers. In this way, the present paper fills a research gap, as previously established in Sections 1 and 2, and extends our knowledge in the field of environmental management systems by:

- Exploring the degree of awareness of TQEM among Chinese manufacturing organisations, including its relationship to a company's size and source;

- Investigating the degree of adoption of TQEM among Chinese manufacturing organisations and establishing its relationship to a company's size and the implementation of TQM;

- Exploring the drivers which motivated Chines manufacturers to adopt TQEM, the results they have obtained from such adoption, and the challenges they faced during its deployment; and

- Helping us to understand the main impeding factors that have stopped Chinese manufacturers from more widely adopting TQEM.

Besides these theoretical contributions, the paper also contributes to the practice of environmental management systems as these contributions are beneficial for managers who aim at effectively adopting TQEM to simultaneously improve the environmental, operational and financial performance of their organisations. Although the present study was particularly focused on the manufacturing sector of China, other industrial sectors such as logistics and transport, healthcare, services, among others, which also have the need of addressing the negative impact of their operations, are also likely to benefit from this study due to the wide 
applicability of TQEM. Like the manufacturing industry in China, all these sectors are receiving increasing pressures from various stakeholders to operate more sustainably.

Generally, the paper provides some interesting insights into the implementation standing of an environmental management approach, i.e. TQEM, in China. This may motivate organisations not currently embarked on the "green wagon" to contemplate the benefits that the implementation of TQEM, or any other environmental management approach, may bring to their operations and business.

In terms of limitations and future research directions, this paper has been mainly confined to an exploratory study which provides light into the application of TQEM. Future research can consider and adopt the findings derived from this research to develop an implementation framework which facilitates the adoption of TQEM. Although this was not an impeding factor to adopt TQEM in the Chinese manufacturing sector, according to the results of this study, it was a relevant factor in the UK's construction sector as suggested by Khadour (2010). Another compounding constraint of this research is the fact that it was only limited to the manufacturing sector of China. Thus, further research is required to provide added insights into the application of TQEM in other industrial sectors and countries. A study of this type will provide further evidence on the role of industry characteristics towards the adoption of TQEM and its contribution to the environmental, operational and business performance of organisations. As this study was particularly focused on industrialists, future studies can also include academic and research experts in order to also obtained a theoreticalbased view on the implementation of TQEM. A combination of both pragmatic and theoretical views will certainly provide a more powerful combination source to not only understand the implementation nature of TQEM but also other environmental management approaches. Finally, also coupling future research with qualitative methods such as interviews can contribute in uncovering more specific details regarding the adoption of TQEM. As these future research directions have been defined based on the limitations of the present study, it has not only brought further light into the environmental management system field but it has also opened new areas for research within this area.

\section{References}

Abdulrahman, M.D., Gunasekaran, A., Subramanian, N. (2014), "Critical barriers in implementing reverse logistics in the Chinese manufacturing sectors", Journal of Cleaner Production, 147(Part B), 460-471.

Al Khidir, Zailani, S. (2009), "Going Green in Supply Chain towards Environmental Sustainability", Global Journal of Environmental Research, 3(3), 246-251.

Al-Najem, M., Dhakal, H., Labib, A., Bennett, N. (2013), "Lean readiness level within Kuwaiti manufacturing industries", International Journal of Lean Six Sigma, 4(3), 280-320.

Antony, J., Desai, D.A. (2009), "Assessing the status of six sigma implementation in the Indian industry", Management Research News, 32(5), 413-423.

Azzara, C.Y. (2010), Beyond lineal thinking - An interactive approach: Questionnaire design for Business Research, Tate Publishing \& Enterprises, Mustang, Oklahoma.

Baskak, M., Mihçıŏlu, E. (2004), Otomotiv endüstrisinde ana firma - tedarikçi ilişkileri ve bir anket uygulamas1, Chamber of Mechanical Engineers, Ankara, available at: www.mmo.org.tr/resimler/dosya ekler/1e567798fc9ccd2 ek.pdf (accessed 13 November 2016).

Beecroft, G.D. (2004), "Evolving quality improvement/implementation strategies", ASQ's Annual Quality Congress Proceedings 2004, Quality Congress, pp. 425-430. 
Binti Aminuddin, N.A., Garza-Reyes, J.A., Kumar, V., Antony, J. (2016), "An analysis of managerial factors affecting the implementation and use of Overall Equipment Effectiveness", International Journal of Production Research, Vol. 54, No. 15, pp. 4430-4447.

Carter, C.R., Ellram, L.M., Ready, K. J. (1998), "Environmental purchasing: benchmarking our German counterparts", International Journal of Purchasing and Materials Management, 34(3), 28-38.

China Briefing (2011), "China Issues Classification Standards for SMEs". China Briefing 7, available at: http://www.china-briefing.com/news/2011/07/07/china-issuesclassification-standards-for-smes.html (accessed on 4 November 2011).

Chung, L., Lo, C.W.H., Li, P.H.Y. (2016), "The interaction effects of institutional constraints on managerial intentions and sustainable performance", International Journal of Production Economics, 181, 374-383.

Curkovic, A.S., Melnyk, S.A., Handfield, R.B., Calantone, R.J. (2000), "Investigating the linkage between total quality management and environmentally responsibly manufacturing", IIEE Transactions on Engineering Management, 47(4), 444-464.

Curkovic, A.S., Sroufe, R., Melnyk, S. (2005), "Identifying the factors which affect the decision to attain ISO 14001", Energy, 30(8), 1387-1407.

Curkovic, A.S., Sroufe, R. (2007), "Total quality environmental management and total cost assessment: An exploratory study", International Journal of Production Economics, 105(2), 560-579.

Curkovic, A.S., Sroufe, R., Landeros, R. (2008), "Measuring TQEM returns from the application of quality frameworks", Business Strategy and the Environment, 17(2), 93-106.

Economy, E.C. (2011), "The river runs black: the environmental challenge to China's future", Cornell University Press.

Florida, R. (1996), "Lean and green: the move to environmentally conscious manufacturing", California Management Review, 39(1), 80-105.

Garza-Reyes, J.A., Parkar, H.S., Oraifige, I., Soriano-Meier, H., Harmanto, D. (2012), “An empirical-exploratory study of the status of lean manufacturing in India", International Journal of Business Excellence, 4(5), 395-412.

Garza-Reyes, J.A. (2015), "Lean and Green - A systematic review of the state of the art literature", Journal of Cleaner Production, 102, 18-29.

Garza-Reyes, J.A., Rocha-Lona, L., Kumar, V. (2015a), "A conceptual framework for the implementation of quality management systems", Total Quality Management \& Business Excellence, 26(11-12), 1298-1310.

Garza-Reyes, J.A., Ates, E.M., Kumar, V. (2015b), "Measuring lean readiness through the understanding of quality practices in the Turkish automotive suppliers industry", International Journal of Productivity and Performance Management, 64(8), 10921112.

GEMI (2017), Total Quality Environmental Management (1993), available at: http://gemi.org/resources/TQE 101.pdf (accessed on 26 July 2017).

Geng, Y., Wang, X., Qinghua, Z., Hengxin, Z. (2010), "Regional initiatives on promoting cleaner production in China: a case of Liaoning", Journal of Cleaner Production, 18(15), 1502-1508. 
Griffith, A. (2002), "Management systems for sustainable construction: integrating environmental, quality and safety management systems", International Journal of Environmental Technology and Management, 2(1-3), 114-126.

Hanna, M.D., Newman, R.W., Johnson, P. (2000), "Linking operational and environmental improvement through employee involvement", International Journal of Operations \& Production Management, 20(2), 148-165.

Harrington, D.R., Khanna, M., Deltas, G. (2008), "Striving to be green: the adoption of total quality environmental management", Applied Economics, 40(23), 2995-3007.

Hayter, A.J. (2012), Probability and Statistics for Engineers and Scientists, $4^{\text {th }}$ edition, Cengage Learning, Boston.

ICEF Monitor (2015), "Number of Chinese outbound students up by $11 \%$ in 2014", Available at: http://monitor.icef.com/2015/03/number-of-chinese-outbound-studentsup-by-11-in-2014/ (Accessed on 05 November 2016).

Khadour, L. (2010), Total quality environmental management (TQEM) framework towards sustainability (UK Novated D\&B Principal Contractors), PhD Thesis, Nottingham Trent University, Nottingham UK.

Khalili, N.R., Duecker, S. (2013), "Application of multi-criteria decision analysis in design of sustainable environmental management system framework", Journal of Cleaner Production, 47, 188-198

Khor, K.S., Udin, Z.M., Ramayah, T., Hazen, B.T. (2016), "Reverse logistics in Malaysia: The Contingent role of institutional pressure", International Journal of Production Economics, 175, 96-108.

King, A.A., Lenox, M.J., Terlaak, A. (2005), "The strategic use of decentralized institutions: Exploring certification with the ISO 14001 management standard", Academy of Management Journal, 48(6), 1091-1106.

Kirkham, L., Garza-Reyes, J.A., Kumar, V., Antony, J. (2014), "Prioritisation of operations improvement projects in the European manufacturing industry", International Journal of Production Research, 52(18), 5323-5345.

Lancaster, G. (2008), Research methods: A concise introduction to research in management and business consultancy, $2^{\text {nd }}$ edition, Routledge, Oxford.

Lau, K.H., Wang, Y. (2009), "Reverse logistics in the electronic industry of China: a case study", Supply Chain Management: An International Journal, 14(6), 447-465.

Lee, T.Y., Wong, W.K., Yeung, K.W. (2011), "Developing a readiness self-assessment model (RSM) for Six Sigma for China enterprises", International Journal of Quality \& Reliability Management, 28(2), 169-194.

Lee, J.H., Garza-Reyes, J.A., Kumar, V., Rocha-Lona, L., Mishra, N. (2013), “A comparative study of the implementation status of Lean Six Sigma in South Korea and the UK", Advances in Sustainable and Competitive Manufacturing Systems, $23^{\text {rd }}$ International Conference on Flexible Automation and Intelligent Manufacturing (FAIM), Porto, Portugal, 26-28 June, Springer.

Liu, Z., Davis, S.J., Feng, K., Hubacek, K., Liang, S., Diaz Anadon, L., Chen, B., Liu, J., Yan, J., Guan, D. (2016), "Targeted opportunities to address the climate-trade dilemma in China", Nature Climate Change, 6, 201-206.

Love, P.E.D., Li, H., Irani, Z., Holt, G.D. (2000), "Rethinking Total Quality Management: Toward a framework for facilitating learning and change in construction organizations", The TQM Magazine, 12(2), 107-116. 
Mallur, S.B., Hiregouder, N.L. and Sequeira, A.H. (2012), "The relationship between TQM practices and business excellence in small and medium sized manufacturing enterprises of north Karnataka region", available at: http://dx.doi.org/10.2139/ssrn.2041439 (accessed 15 November 2016).

McLaughlin, P. (2013), "Manufacturing best practice and UK productivity", Future of Manufacturing Project: Evidence Paper 21, Government Office for Science, Available https://www.gov.uk/government/uploads/system/uploads/attachment_data/file/283895 /ep21-manufacturing-best-practice-uk-productivity.pdf (Accessed on 06 November 2016).

Min, H., Galle, W.P. (2001), "Green purchasing practices of US firms”, International Journal of Operations and Production Management, 21(9), 410-417.

Narasimhan, R., Schoenherr, T. (2012), "The effects of integrated supply management practices and environmental management practices on relative competitive quality advantage", International Journal of Production Research, 40(4), 1185-1201.

Nidumolu, R., Prahalad, C.K., Rangaswami, M.R. (2010), "Why sustainability is now the key driver to innovation", Harvard Business Review, 87(9), 56-64.

O’Neill, R., Sohal, A., Teng, C.W. (2016), "Quality management approaches and their impact on firms' financial performance - An Australian study", International Journal of Production Economics, 171(Part 3), 381-393.

Pingyu, A.Y., Yu, B.Y. (2010), "The barriers to SMEs' implementation of lean production and countermeasures - based on SMS in Wenzhou', International Journal of Innovation, Management and Technology, 1(2), 220-225.

Qi, G.Y., Zeng, S.X., Tam, C.M., Yin, H.T., Wu, J.F., Dai, Z.H. (2013), "Diffusion of ISO 14001 environmental management systems in China: rethinking on stakeholders' roles", Journal of Cleaner Production, 19(11), 1250-1256.

Robson, C., McCartan, K. (2016), Real world research. $4^{\text {th }}$ edition, John Wiley \& Sons, Chichester.

Sarkis, J., Gonzalez-Torre, P., Adenso-Diaz, B. (2010), "Stakeholder pressure and the adoption of environmental practices: The mediating effect of training", Journal of Operations Management, 28(2), 163-176.

Sezen, B., Karakadilar, I.S. and Buyukozkan, G. (2012), "Proposition of a model for measuring adherence to lean practices: applied to Turkish automotive part suppliers", International Journal of Production Research, 50(14), 3878-3894.

Soltani, E., Lai, P., Gharneh, N.S. (2005), "Breaking through barriers to TQM effectiveness: Lack of commitment of upper-level management", TQM \& Business Excellence, 16(8/9), 1009-1021.

Stalley, P. (2009), "Can trade green China? Participation in the global economy and the environmental performance of Chinese firms", Journal of Contemporary China, $18(6), 567-590$.

Taj, S. (2008), "Lean manufacturing performance in China: assessment of 65 manufacturing plants", Journal of Manufacturing Technology Management, 19(2), 217-234.

Talib, F., Rahman, Z., Qureshi, M.N. (2011), "Analysis of interaction among the barriers to total quality management implementation using interpretive structural modeling approach", Benchmarking: An International Journal, 18(44), 563-587.

Teixeira, A.A., Chiappetta Jabbour, C.J.C., Lopes de Sousa Jabbour, A.B., Latan, H., Caldeira de Oliveira, J.H. (2016), "Green training and green supply chain 
management: evidence from Brazilian firms", Journal of Cleaner Production, 116, $170-176$.

The Economist (2015), "Made in China", available at: http://www.economist.com/news/leaders/21646204-asias-dominance-manufacturingwill-endure-will-make-development-harder-others-made (accessed on 21 September 2016).

Tseng, M.L., Lin, Y.H., Chiu, A.S. (2009), "Fuzzy AHP-based study of cleaner production implementation in Taiwan PWB manufacturer", Journal of Cleaner Production, 17(14), 1249-1256.

Vachon, S. (2007), "Green supply chain practices and the selection of environmental technologies", International Journal of Production Research, 45(18-19), 4357-4379.

Vouzas, F., Psychogios, A.G. (2007), "Assessing managers' awareness of TQM", The TQM Magazine, 19(1), 62-75.

Wei, Y., Balasubramanyam, V. (2015), “A comparative analysis of China and India's manufacturing sectors", Economics Working Paper Series, Lancaster University, available at: https://www.lancaster.ac.uk/media/lancaster-university/contentassets/documents/lums/economics/working-papers/LancasterWP2015 003.pdf (accessed on 01 November 2016).

Wang, H., Bi, J., Wheeler, D., Wang, J., Cao, D., Lu, G., Wang, Y. (2004), "Environmental performance rating and disclosure: China's GreenWatch program", Journal of Environmental Management, 71(2), 123-133.

Watson, P.A., Griffith, A., Stephenson, P. (2000), Management Systems for Construction, Longman, NY.

Wiengarten, F., Pagell, M. (2016), "The importance of quality management for the success of environmental management initiatives", International Journal of Production Economics, 140(1), 407-415.

Xue, B., Chen, X., Geng, Y., Guo, X., Lu, C., Zhang, Z., Lu, C. (2010), "Survey of officials' awareness on circular economy development in China: Based on municipal and county level", Resources, Conservation and Recycling, 54(12), 1296-1302.

Yuan, Z., Bi, J., Moriguichi, Y. (2006), “The Circular Economy: A new development strategy in China, Industrial Ecology in Asia, 10(1-2), 4-8.

Yusuf, Y., Gunasekaran, A., Dan, G. (2007), "Implementation of TQM in China and Organisation Performance: An Empirical Investigation”, TQM \& Business Excellence, 18(5), 509-530.

Zeng, S.X., Tam, C.M., Tam, V.W.Y., Deng, Z.M. (2005), “Towards implementation of ISO 14001 environmental management systems in selected industries in China", Journal of Cleaner Production, 13(7), 645-656.

Zeng, S.X., Liu, H.C., Tam, C.M., Shao, Y.K. (2008), "Cluster analysis for studying industrial sustainability: an empirical study in Shanghai", Journal of Cleaner Production, 16(10), 1090-1097.

Zeng, S.X., Meng, X.H., Yin, H.T., Tam, C.M., Sun, L. (2010), "Impact of cleaner production on business performance", Journal of Cleaner Production, 18(10), 975983.

Zhan, Y., Tan, K.H., Ji, G., Chung, L., Chiu, A.S.F. (2016), "Green and lean sustainable development path in China: Guanxi, practices and performance", Resources, 
Conservation and Recycling, DOI: http://dx.doi.org/10.1016/j.resconrec.2016.02.006 (in press).

Zhang, W., Wang, W., Wang, S. (2014), "Environmental performance evaluation of implementing EMS (ISO 14001) in the coating industry: case study of a Shanghai coating firm”, Journal of Cleaner Production, 64, 205-217.

Zhu, Q., Sarkis, J., Geng, Y. (2005), "Green supply chain management in China: pressures, practices and performance", International Journal of Operations \& Production Management, 25(5), 449-468.

Zhu, Q., Sarkis, J., Lai, K. (2008), "Confirmation of a measurement model for green supply chain management practices implementation", International Journal of Production Economics, 111(2), 261-273.

Zhu, Q., Geng, Y., Lai, K. (2010), "Circular economy practices among Chinese manufacturers varying in environmental-oriented supply chain cooperation and the performance implications", Journal of Environmental Management, 91(6), 13241331.

Zhu, Q., Cordeiro, J., Sarkis, J. (2012), "International and domestic pressures and responses of Chinese firms to greening", Ecological Economics, 83, 144-153.

Zhu, Q., Cordeiro, J., Sarkis, J. (2013), "Institutional pressures, dynamic capabilities and environmental management systems: Investigating the ISO 9000-Environmental management system implementation linkage", Journal of Environmental Management, 114, 232-242.

$\mathrm{Zu}$, X., Fredendall, L.D., Douglas, T.J. (2008), “The evolving theory of quality management: The role of Six Sigma”, Journal of Operations Management, 26(5), 630-650. 